\title{
Liposome-Encapsulated Doxorubicin Citrate
}

National Cancer Institute

\section{Source}

National Cancer Institute. Liposome-Encapsulated Doxorubicin Citrate. NCI Thesaurus.

Code C61317.

A formulation of the citrate salt of the antineoplastic anthracycline antibiotic doxorubicin, encapsulated within liposomes, with antitumor activity. Doxorubicin intercalates into DNA and interacts with topoisomerase II, thereby inhibiting DNA replication and RNA synthesis. This agent also interacts with cell membrane lipids causing lipid peroxidation. Liposomal delivery of doxorubicin improves drug penetration into tumors and decreases drug clearance, thereby increasing the duration of therapeutic drug effects while lowering the toxicity profile. 